\title{
The Research and Implementation of a Personalized Intelligent Tutoring System
}

\author{
Lv Saidong and Tang Guohua \\ Institute of Security \\ Yunnan Normal University \\ Kunming,Yunnan Province,China \\ lsdong_km@sina.com
}

\author{
Xia Yaowen and Sun Yu \\ Institute of Information \\ Yunnan Normal University \\ Kunming,Yunnan Province,China \\ xywen_km@sina.com
}

\begin{abstract}
Personalized intelligent tutoring system is an effective approach to achieve the personalized teaching. In this paper, it discusses the connotation and learning styles of personalized intelligent tutoring system. After research the knowledge model and the student model. Finally, it achieves a personalized intelligent tutoring system prototype, and it is applied to the data structures course. It has well received by teachers and students praise.
\end{abstract}

Keywords-Personalized Intelligent Tutoring System, Knowledge Model, Knowledge Node

\section{INTRODUCTION}

Intelligent tutoring system is one of the most import applications where artificial intelligence technology is used in network teaching. The teaching program should be flexible; students should be positive, proactive, conscious, assertive learning, which fully reflects the subjectivity of student learning and adaptive teaching. In the current network teaching platform, a common problem is that the content of the curriculum is too rigid, so it is difficult to organize personalized learning. The current teaching system can not be carried out according to the situation of the students' own abilities, students can not demand learning; No matter what level of student access to the teaching system and to see the content of almost all the same; Students can select learning content and learning progress only, so that the network teaching efficiency and quality are reduced.

The network intelligent tutoring system can automatically adapt to the requirement of students, provide personalized teaching and improve teaching quality and efficiency. It will be the inevitable trend of development and the long-term goal which the educators have long pursuit and explore in the future network teaching.

\section{PERSONAL TEACHING}

Personalized teaching activities are implemented according to the personality traits of the learners, it provide the best learning methods and strategies according to learners' personalized requirement [1]. It become selfcreation and self-seeking teaching activities from the entire teaching process, a holistic, well-designed to promote active learning to accommodate. It emphasizes self-development and personality development of the students. Personalized teaching motivate learners to take the initiative, to actively participate in the teaching and learning activities, capacity development, and comprehensively improve their own quality, so that it can adapt to the needs of social development.

Many personalized teaching try to accommodate individual difference form the desire of the learner. The Adaptive Learning Environments Model emphasizes the importance of student's choice [2]. Student's choice become an important factor in promote learning motivation and learning responsible. In addition, the more successful the students more actively in learning motivated to learn. The system offers four learning styles for learners to choices which are Theorists, Activists, Progmaticists, Reflectors. Students' learning style is not the same as learning the contents of the presentation will be different.

\section{THE DESIGN OF PERSONALIZED INTELLIGENT TUTORING SYSTEM[3][4]}

\section{A. Knowledge representation}

The content organization of personalized network course has good navigation structure based web page, and the content organization and description according to the students' cognitive. The course content using a modular organization, the division of the module should be relatively independent, and it can be base on knowledge points. The knowledge point division and representation which is based on characteristics of network teaching is a key problem.

Personalized intelligent tutoring system's main goal is to help the different students master a particular field of knowledge, and apply this knowledge to solve the problem. Knowledge of a particular area is composed by a number of knowledge point, knowledge points is a knowledge collection which ensure that the teaching content is relatively complete partial. The text, images, animation, video, film, audio files of each knowledge points required by the teaching courseware material composition. If the students reached the requirements for the degree of master of all knowledge in the field, thus think that students have master the knowledge in the field. Therefore, design the knowledge base of intelligent tutoring system, it is first domain knowledge is divided into a number of knowledge points, and then analyzes how these knowledge stores in the domain knowledge base. In this paper, knowledge point representation divides into three layers, the first layer is course layer, the second layer is the knowledge class and the third layer is the knowledge points. The knowledge point representation is shown in Figure 1. And the knowledge 
point representation store in SQL Server 2000 is shown in Figure 2.

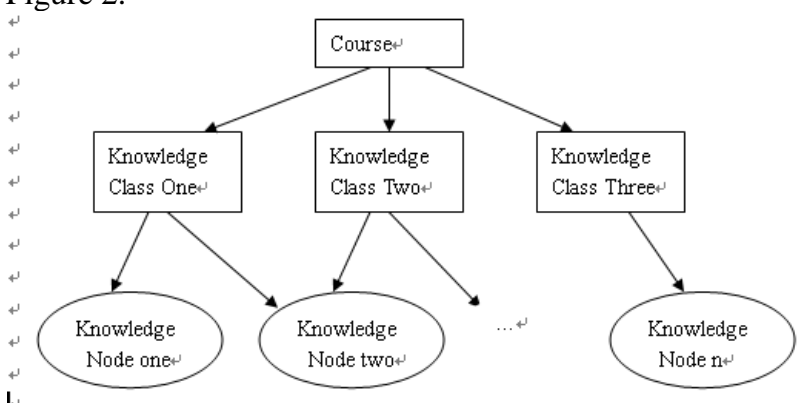

Figure 1. . The knowledge point representation

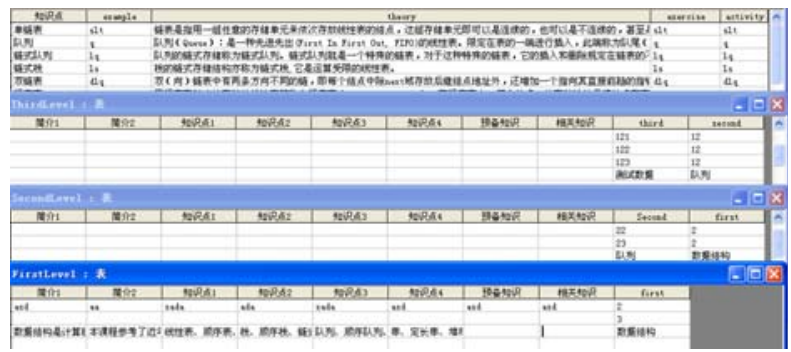

Figure 2. The knowledge point representation store in SQL Server2000

\section{B. Student Model}

The goal of personalized intelligent tutoring system is to arouse the students' learning enthusiasm, and hope to achieve the best personalized teaching. How to create the students' model is a primary key which relate to the quality of personalized service of the students.

Definition 1. Student Model(SM)

Student model refers to the detailed description of the student attributes, which is a four-tuple, described as follows:

$\mathrm{SM}=$ (Personal Information, Real -Time Information, Real -Time Information, Status Information, LearningHistory Information)

Definition 2. Personal Information (PI)

Personal information refers to the situation of students' personal information which is related to personal teaching learning system. Described as follows:

$\mathrm{PI}=$ (student no, student name, student pwd, student sex, student age, learning style, learning preferences)

Definition 3.Real-time Information (RI)

Real-time information is a collection of the students' temporarily saved information which is teaching resources, personality preferences, teaching schedule in the learning process. Described as follows:

$\mathrm{RI}=$ ( student no, resource id ,learning time, current speed, teaching schedule)

Definition 4.Status Information (SI)

Status information is a description of the state of students' overall learning. Described as follows:

$\mathrm{SI}=($ student no, student ability, study status, preference)

Definition 5. Learning- History Information (LI)
Learning- History Information is reserved for students past learning state. Described as follows:

LI= (student no, study long time, studied knowledge, studied log)

In this paper, the definition of each model respectively stored in the SQL Server2000 in a table, among these tables associated student NO. Such as personal information model stored in the corresponding SQL Server2000 database shown in Figure3.

\begin{tabular}{|c|c|c|c|c|}
\hline & 列名 & 数据类型 & 长度 & 允许空 \\
\hline$\triangleright$ & 学号 & int & 4 & \\
\hline & 密码 & char & 10 & $\checkmark$ \\
\hline & 性别 & bit & 1 & $\checkmark$ \\
\hline & 姓名 & nchar & 10 & $\checkmark$ \\
\hline & 年龄 & int & 4 & $\checkmark$ \\
\hline & 学习风格 & char & 10 & $\checkmark$ \\
\hline & 偏好 & char & 10 & $\checkmark$ \\
\hline
\end{tabular}

Figure 3. Personal information model stored in the corresponding SQL Server2000 database

\section{The IMPLEMENTATION OF PERSONALIZED INTELLIGENT TUTORING SYSTEM}

\section{A. The learning process of personalized intelligent tutoring system}

When learners enter the system, it extract the appropriate the learners information to provide personalized service by query the students' information base to determine the identity of the learner. If the learner information database can not find learner's information, the learner must to register. The registered module is shown in figure 4.

\begin{tabular}{|c|c|c|c|}
\hline \multicolumn{4}{|c|}{ 添加用户 } \\
\hline 用户名： & \multicolumn{2}{|l|}{ Isd } & \\
\hline 密 码： & \multicolumn{2}{|l|}{$\bullet \bullet \bullet \bullet$} & \\
\hline 性别： & \multicolumn{2}{|l|}{ 女 $v$} & \\
\hline 电子邮件： & \multicolumn{2}{|l|}{ Isd@126.com } & \\
\hline 学习风格： & \multicolumn{3}{|c|}{ Activists $\quad \mathrm{V}$} \\
\hline 多媒体偏好： & \multicolumn{3}{|c|}{ Visual $\quad v$} \\
\hline 知识水平： & \multicolumn{3}{|l|}{ 中 } \\
\hline 用户期望： & \multicolumn{3}{|c|}{ 数据结构实用的知识点 } \\
\hline & & 添加 & 重置 \\
\hline
\end{tabular}

Figure 4. register module

The learner register must fill in personal information, learning style, multimedia preferences and knowledge level. The system will make a preliminary assessment of the user based on this registration information, and use this to determine the starting point of student learning, thus it provide the appropriate starting point for teaching resources for student to learn and registration information stored as a new student information to student information library. The 
system has the following characteristics. The user select a different learning style, the presentation of the teaching resources are not the same. Learners' learning style is determined; the system according to the learner's style to the learner's learning proposals. The system provides to the learner the choice of different style of learning interface; The learner can choose to match with the learning style learning interface of measurement results; The learner can also be select another the learning style not the system provide.

\section{B. System implementation}

The system has been on-line at:http://202.203.225.2 in six months ago. Server-side environment of system is Windows Server 2003 and Internet Information Server, database of system is SQL Server2000.Currently, the system has a complete course on data structure. The system is running in good condition, course content, user interface and personalized navigation since the on-line testing has well received by teachers and students praise.

\section{MODULES}

\section{A. Main learning modules}

Main learning modules consists of three parts, the first part (left side of the interface) which contains knowledge point unit and title, is a teaching resource tree structure. The second part (main side of the interface) presents the appropriate knowledge unit teaching content. The third part (bottom of the interface) presents personalized reminders and navigation state. The main learning module is shown in Figure 5.

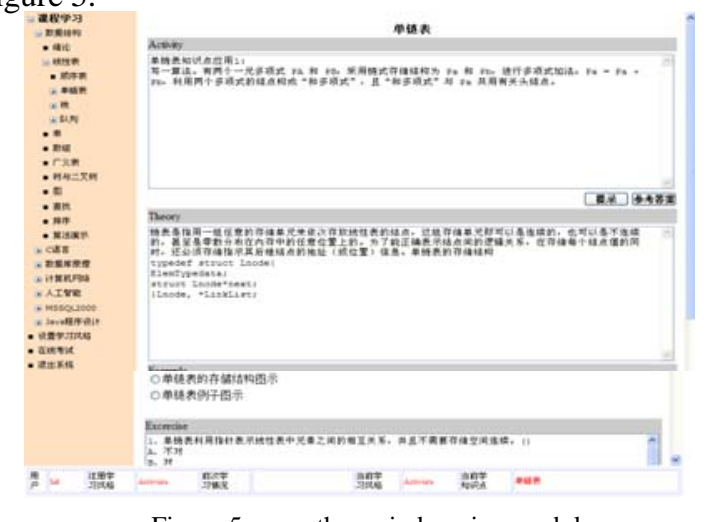

Figure 5. the main learning modules

\section{B. Quiz module}

Quiz module includes unit quiz and integrated quiz. After user learns each part can quiz. System includes only false questions, choice and multi-choice now. After the quiz is completed, the system will be the answer to the user's analysis pointed out that the lack of user learning and make recommendations. The quiz module is shown in Figure 6.

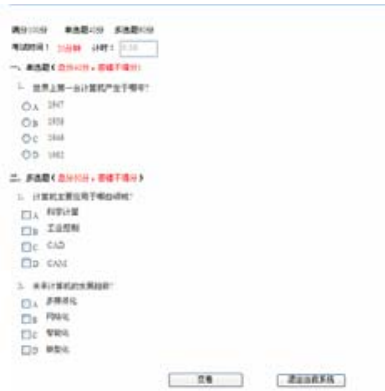

Figure 6. quiz module

\section{CONCLUSIONS}

In this paper, it proposes a personalized strategy of network teaching based on learning style. System can be given courses guidance, personalization tools according to the learning style of the learner, and guide the learning process, providing a different learning content. It is to achieve a personalization in certain degree [5]. The system has a very visual and friendly user interface and well received by teachers and students praise. We will also make further improvements.

\section{ACKNOWLEDGMENT}

This work is supported by the National NSF of China (No.60903131), the key project of the Education Bureau Youth Fund of Yunnan Province (No.07Z1066).

\section{REFERENCES}

[1] Li Qilong Personalized teaching and research. East Normal University Doctoral Dissertation,2000

[2] Li Ruming,Liu Jinyu. The connotation and characteristics of personalized teaching. Educational theory and practice. 2001,21(9):37-40.

[3] Deng Zhiwei.The course research of personalized teaching.Foreign educational materials. 2000,(2):34-38.

[4] Hall Thomas E. , Critical thinking, self-direction and online learning : A practical inquiry perspective in higher education, Dissertation Abstracts International. 2004, 66(04) : 1243.

[5] A.Th. Schreiber,et,Knowledge Engineering and Mangement. The MIT Press,Cambridge,MA,2000 